\title{
Child Freedom in Mobility to School: Measuring the Strong Factors of Choice of Mode among Parents
}

\author{
Nurul Shakila Khalid ${ }^{1}$, Na'asah Nasrudin², Marlyana Azyyati Marzukhi $^{3}$ \\ ${ }^{1}$ Centre of Studies for Town and Regional Planning, Faculty of Architecture, Planning and Surveying, Universiti Tekonologi MARA, \\ Puncak Alam, Selangor, 42300 Malaysia \\ shakilakhalid@uitm.edu.my,naasa717@uitm.edu.my,marlyana@uitm.edu.my \\ Tel of 1 st Author: +60 12-738 1457
}

\begin{abstract}
The research aims to examine how school children's characteristics may contribute to the choice of mode to school while testing how different neighbourhood density and design may influence the freedom to mobility. Findings indicate that children living in the denser neighbourhood are significantly associated with independent mobility to school compare to children live in a low-density neighbourhood that reported the independent mobility has considerably decreased. Children's preferences for being driven coincide with parents' fears for children safety and concern their children's ability to travel independently in an unsafe neighbourhood environment besides the school profile.
\end{abstract}

Keywords: School Children, Independent Mobility, Density

eISSN: 2398-42870 2021. The Authors. Published for AMER ABRA cE-Bs by e-International Publishing House, Ltd., UK. This is an open access article under the CC BYNC-ND license (http://creativecommons.org/licenses/by-nc-nd/4.0/). Peer-review under responsibility of AMER (Association of Malaysian Environment-Behaviour Researchers), ABRA (Association of Behavioural Researchers on Asians/Africans/Arabians) and CE-Bs (Centre for Environment-Behaviour Studies), Faculty of Architecture, Planning \& Surveying, Universiti Teknologi MARA, Malaysia.

DOI: https://doi.org/10.21834/ebpj.v6iSI4.2895

\subsection{Introduction}

A city should be constructed as it is safely navigable by seven-year-old on a bicycle. Enrique Penalosa, a former Mayor of Bogota, Colombia.

The statement above does reflect the questions of how can urban planners integrate the environmental experiences that children have into the process of designing a city, and does the loss of children's freedom matter to planning as overall? The freedom of children to independently explore their neighbourhood environment is of far more value than we may first realize. With obesity rates and road accidents increasing, and social capital decreasing among children (Hannah et al., 2017), children's freedom of movement, in combination with diverse environmental affordances to learn, facilitate play and living, is fundamentally important in creating a childfriendly environment. According to Urry (2016), there are the licenses given to the children by their parents - license to commute to school alone, catch buses alone, cross the main road alone, and play in the playground with friends. The age at which children are given these license becomes an indicator of the level of freedom that children have or their level of independent mobility. For example, according to Waygood and Susilo (2015), children in Japan and German were likely to be given this license of freedom for children aged 9, 10, 11 and 12. Very low numbers of Japan and German children were driven to school compared to children in Singapore.

eISSN: 2398-4287C 2021. The Authors. Published for AMER ABRA cE-Bs by e-International Publishing House, Ltd., UK. This is an open access article under the CC BYNC-ND license (http://creativecommons.org/licenses/by-nc-nd/4.0/). Peer-review under responsibility of AMER (Association of Malaysian Environment-Behaviour Researchers), ABRA (Association of Behavioural Researchers on Asians/Africans/Arabians) and cE-Bs (Centre for Environment-Behaviour Studies), Faculty of Architecture, Planning \& Surveying, Universiti Teknologi MARA, Malaysia.

DOI: https://doi.org/10.21834/ebpj.v6iSI4.2895 
In Australia and the UK, the rates of walking to/from school shows the declining and remain low (Broberg and Sarjala, 2015). For example, between 2011 and 2015 in Australia, rates of walking to school daily declined from $48 \%$ to $31 \%$, while rates of cycling to school also show the declining; from $21 \%$ to $10 \%$. Even in other developed countries such as Norway, Denmark and Finland that often have high rates of independent mobility among children, increasing trends towards car travel to school have been reported.

The important reasons lie behind this ongoing trend of car-oriented mobility are complex, but the built environment in which homes and schools are located, and the complexity and time pressures of modern family life, urban form, more mothers in paid employment may play an important role in producing behavioural change. The growing complexity of family lifestyles has resulted in school trips being combined with parental commutes to work, trips to shops or any other structured activities. This behavior is described as trip chaining where smaller trips are combined into a larger trip chain. For example, a parent's trip chain may comprise a journey from home to work via their younger child's kindergarten and their older child's primary school for drop-off purposes. The tendency to drive children to school may be exacerbated where the parent's trip chain involves usual travel; home-school-work. Although the association is indefinite due to the many findings, decisions on the children travel behavior, choice of mode, accompaniment and trip chaining are often made at a socio-demographic characteristic. Household income, age, gender, car ownership, employment and population density are associated with trip chaining decisions.

Despite the increasing of carbon emissions in urban areas, being driven to school may be normalized due to increased car availability, time constraints, perceived convenience, parents' perceptions of safety (regarding the risks of both pedestrian accident and stranger danger) and travel complexity. The impacts of these ongoing socio-demographic shifts have initiated a critical debate on urban planning discourses for their inclusiveness of family life in cities. Given that background of families may influence with children active and independent travel (Mitra and Buliung, 2015). Families of lower-income face challenges related to housing prices, quality of housing, services and living in less than desirable neighbourhood (Sarmiento et al, 2015 and Rothman et al., 2015). What this implies for urban planning is redefining the nature of planning for families in urban areas. He and Giuliano (1990) and Hannah et al., (2017) have found the lack of understanding by urban planners of the importance of the local scale in the everyday lives of children and their parents and plea for more family-inclusive policies. In the UK, several intervention programs such as "Walk to School" campaigns, walking school buses and school travel coordinators have been carried out that aimed at children. Additionally, in the lack of evidence on effectiveness a growing literature on the predictors of children's independent mobility to school has emerged to help inform policy interventions.

To understand these problems, several scholars explored the relationships between children travel behaviours to school and the neighbourhood characteristics; design, density and distance (Broberg and Sarjala, 2015; Curtis et al., 2015 and Sharmin and Kamruzzaman, 2017). Supported by Broberg and Sarjala (2015), children living in denser neighbourhoods and mixed land use were more likely to walk for school. Larsen, Buliung and Faulkner (2015) found that factors such as distance to destination, block density, walking density, signalised intersections, mixed land use and schools in low-income neighbourhoods were positively associated with active and independent mobility among children at the age of 10 . There has been an observation that the denser the urban structure, particularly when locating a mix of uses near each other, is less dependent on private vehicles. This also suggests by Rojas et al., (2017) that stated in Hong Kong, high shade-tree density and covered pathway as to overcome the issue of climatic encouraged children to walk to school independently. Contrary, large city block sizes and increased numbers of intersections discouraged children from walking to school independently. McDonald and Aalborg (2009) indicate that $75 \%$ of Californian children living within 800 meters of school travel by walking or cycling and only $18 \%$ of those residing 1.6 -2.4 km from school travel by active modes. Moreover, Black et al. (2001) state that almost any distance is chosen; some children walk to school. Parental perception is relevant here; another may see a distance that a parent perceives to be too far to walk as reasonable.

To address the above need, this research aims to examine how socio-demographic characteristics may affect the choice of mode to school while testing how built environment characteristics in different neighbourhood density may influence the child freedom in mobility. The main hypothesis is being tested - distances commuted, density and mode differ between socio-demographic characteristics. Supported by Wong et al., (2011), and Pont et al., (2009) that walking to school have consistently been negatively associated with distance, but positively associated with population density (McDonald, 2007; Mitra et al., 2008; Wong et al., 2011). Thus the research aims to answer the following questions; (i) how can the role of distance and housing density be expanded to address the factors influencing the choice of mode, (ii) how can socio-demographic attributes influence the travel behaviour, and (iii) how can exist built environment indicators focused on child-friendliness be developed through descriptive quantitative, qualitative and design knowledge? This research also has an advocacy role as it is concerned with identifying the perceived barrier to encourage walking to school so that these might be addressed and overcome.

\subsection{Literature Review}

\subsection{Built Environmental Factor}

Many studies of children's school travel behavior have demonstrated that the built environment including land uses, transportation infrastructure, and urban form has direct effect on mode of travel choice may encourage active travel particularly walking. Stewarts (2011) review of 42 studies found 480 correlates including distance to school, household income, concern about traffic and crime en route, parental views on walking and cycling and family timetables. The built environment factors Stewart (2011) identified from other studies cover active transport infrastructure, barriers, network connectivity, land use mix, walkability and residential density. According to Ikeda et al., (2018), children living in neighbourhoods with higher residential density and mixed land use were more likely to walk school travel purposes. With regard to transportation infrastructure, some researchers have found that higher street density associates 
with walking among children. Besides, positive correlations have been reported between the presence and density of sidewalks and streetscape. The effect of the neighbourhood built environment has been explored using different spatial units in different studies. Some studies, for example, the built environment was measured within a 400 meter (Mitra et al., 2010 and Schlossberg et al., 2006), 800 meter (Larsen et al., 2009) or $1 \mathrm{~km}$ (Kerr et al., 2006) straight line buffer distance of a child's home or school locations.

In the context of school travel behavior research, the modern planned neighbourhood unit emerged in the early 1900 s. The design principles of a neighbourhood unit emphasized separation between home and work, and a hierarchical street system. Schools, community centres and facilities were planned as central features of a neighbourhood, with surrounding residential development scaled to be within a convenient walking distance such as $\mathbf{4 0 0}$ meter from the these facilities. Many planners assumed that within the boundaries of a neighbourhood, non-residential activities of residents will flow toward the core. However, this neighbourhood planning goal never fully materialized because most neighbourhood centers did not offer essential and desired services. Instead, these suburban neighbourhoods have led to an increase dependency on vehicles. Within this context, previous research has indicated that the physical extent of a neighbourhood unit may be less important to households, and that a household's perceived neighbourhood boundary can be defined based on the action space within which the household perform their daily activities and consume goods and services.

\subsection{Parents Perception and Decision-Making}

Parents are the key decision-makers regarding school travel mode, with parents' perceptions of traffic safety being an important factor in the decision-making process. Several theoretical models have emerged describing the importance of parental perceptions of traffic danger and the built environment when considering school transportation mode. However, some studies such as in Rothman et al., (2015) have reported negative relationships between perceived traffic danger safety risk and walking to school. Here, age is a significant factor in influencing levels of independent mobility among children. It is often a determinant of when children are ready to navigate the neighbourhood alone or the streets safely. The concept of mobility licenses was first proposed by Hilman et al., (1990) to investigate when parents would ready to allow their children to do things outside of home independently such as leave school alone or with friends, cross the streets, or play at the park. Parental perceptions on neighbourhood safety and belief in their child's ability to navigate these potential hazards have already been shown to influence children's travel behaviour significantly. A study by Schoeppe (2015) mentioned this as the "maternal perception of the positive potentiality of outdoor autonomy", such as how the parent decides if her child is ready to navigate the neighbourhood independently, judged by daily ability to take care of themselves, being responsible, and socializing skills. However, although the improvement of neighbourhood environmental conditions led to active transport fulfilling, such as widen street, safe crossings, sidewalks, and bicycle lanes, many children still depend on the car as their main transportation mode. For example, children and parent attitudes regarding the convenience of active modes of transportation and their lack of motivation have been mentioned as barriers. Parental modelling behaviour of active travel has been associated with children's active travel to school, reinforcing that parental views may be the key social environment influences on children's travel behaviours during the first years of life.

\subsection{Socio-Demographic Factors}

The socio-demographic factors such as adult age, sex, parental status, education level, and socio-economic disadvantage may influence parents' willingness to grant children active travel mode have received little attention in many literatures. Previous studies have mainly focused on child-related socio-demographics and consistently found that children age and sex determine parent's willingness to grant children freedom in a mode of choice to school. Schoeppe et al. (2015) examined that parental status, level of education and perceived neighbourhood social cohesion were significantly associated with distances parents would permit for children's active travel. The research founds parents of younger children aged between 0-12 years were less likely to permit children greater distances for active travel than parents of older children (above 13 years). Parents with lower education levels were less likely to grant children greater travel distances than parents with higher education levels. In addition, women were also less likely to grant children greater travel distances than men. However, these relationships did not reach statistical significance $(p=0.068)$.

This outcome is in line with other research that demonstrates women are more cautious than men, and they spend more time taking care of children than men. Hence, they may be more vigilant about potential safety hazards associated with active travel.

\subsection{Methodology}

Focusing on school travel, the self-administrated questionnaires have been distributed to two (2) primary school in different housing density to identify the socio-demographic attributes of school children. Many previous study focus on inner urban and suburban neighbourhoods which do not much reflect the diversity of residential patterns in which children live, the variety of activities they can access within their neighbourhood, or their access to multiple modes of transport. The chosen of SK Bukit Jelutong is because Bukit Jelutong is an elite residential area with its gross density is 6 units per acre along with the walkable built environments as per designed, well-designed of pedestrian infrastructures (sidewalks and crosswalks) and flat topography but private cars is increasing common. The total number of houses in Bukit Jelutong is 880 units mixed with detached, semi-detached and medium high-cost apartment, with the total estimated population is approximately 3,500 people (refer to Fig. 1). For SK Seksyen 18, Shah Alam was chosen because the mixed-use development and it gross residential density are 16 units per acre, but both school located in the centre of neighbourhood areas and within the walking distance (refer to Fig. 2). In Seksyen 18, the total number of houses are 1,430 units which consist of the low and medium terrace houses with the estimated population is 5,700 people residing in Seksyen 18.

A large sample of 10 to 12 year old boys and girls from both school, participated. This was considered to be the most relevant approach to collect data of subjective perceptions and feelings across a large number of school children, supplemented by data on their 
school travel characteristics provided by their parents. The children are from three (3) groups of Standard 4,5 and 6 . The study chose this age group because existing literature on children's school travel patterns reported that 10 to 12 year old tend to walk more or cycling for school trips with or without the adult supervision as mentioned in Sarmiento et al. (2015). In total, data from 135 and 162 of children parents respectively from SK Bukit Jelutong and SK Seksyen 18 were obtained after they receive an informative letter about the study with an invitation to participate in the study (responses rate $=82 \%$ ). Every child was given a questionnaire to be completed by one of the parents. The parental questionnaire contained questions concerning socio-demographic characteristics, neighbourhood environmental perceptions which assessing using a standardized scale and the level of children independent mobility using a standardized scale. Parents completed the questionnaire at home. A week later, parental questionnaires have been collected by the researcher and analysed using descriptive analysis. To measure the distance from home to school, geographic coordinates of school location were provided within $800 \mathrm{~m}$ radius of the school. Distance to school using the shortest street network distance between home and school was measured using ArcGIS 10.4 software.

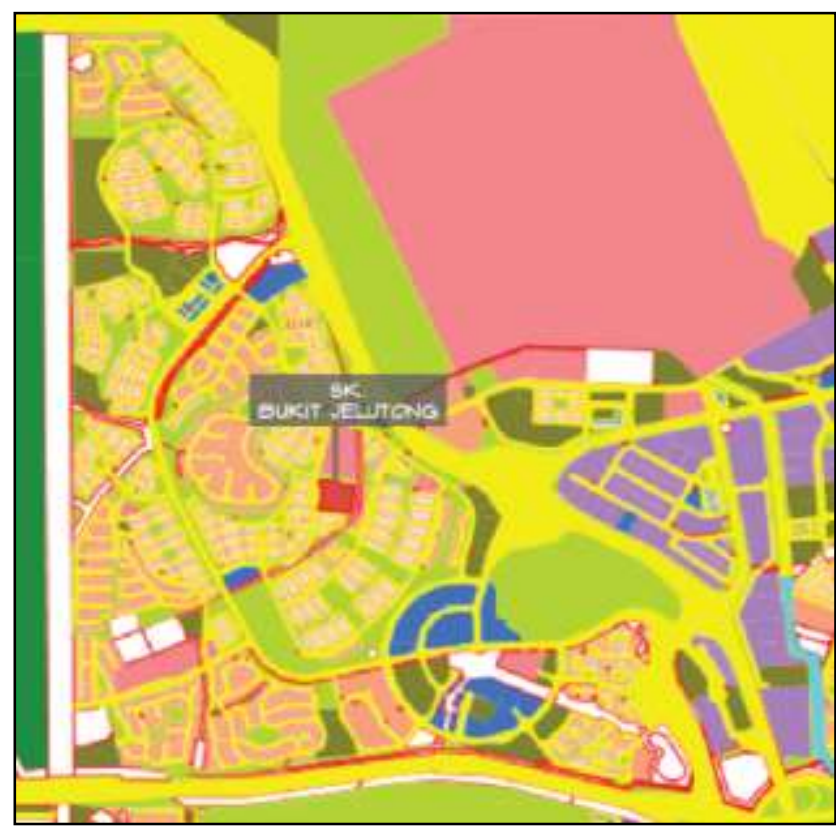

Fig. 1: Short block lengths, many intersections, accessible to many destinations and low density in Bukit Jelutong should encourage children to walk or cycle to/from school.

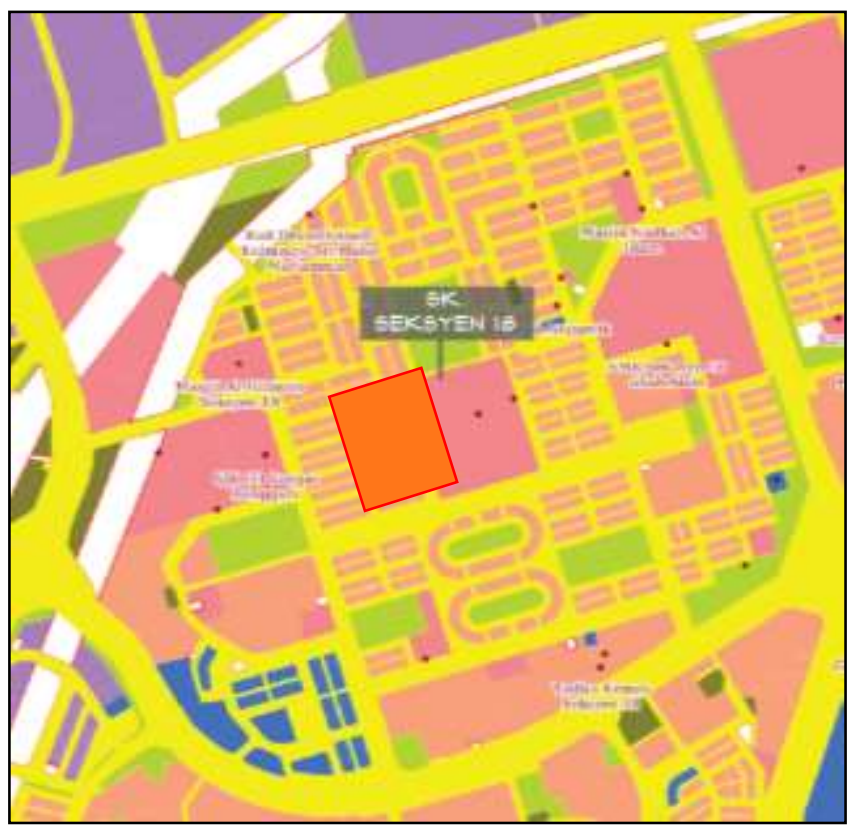

Fig. 2: The focus of built environment in Seksyen 18 was on the high connectivity; grid network and short block lengths to encourage walking.

\subsection{Findings and Discussion}

For this research, three (3) analyses were conducted in two (2) different neighbourhood gross density (houses per acre) and built environment characteristics; (i) Bukit Jelutong with lower density houses and curvilinear pattern, and (ii) Section 18 Shah Alam is medium density and gridiron pattern. Built environment characteristics; density, diversity and design were identified from a literature review. However, this research only focuses on the density of the houses. The first analyses portray the socio-demographic and household economic background. The second and third analysis present descriptive analyses of children mobility pattern and parents perception of neighbourhood characteristics.

\subsection{Children Socio-Demographic and Household Economic Background}

The survey collects a number of social background and household-level characteristics that producing the school trips including the information on children age, gender, number of children in primary school, household income, employment status, parents education and number of car ownership are presented in descriptive analyses (see Table 1). The data socio-demographics were also compared between two different neighbourhoods; Bukit Jelutong and Seksyen 18 to identify to what extent the socio-demographic characteristics in the different neighbourhood may affect the parents' decision on the choice of mode.

Most children as an average of $74 \%$ in both neighbourhoods had at least one adult career as full-time employment and $30 \%$ in households with $2-3$ of cars ownership. This supported by the literature review of children's independent mobility and active travel to school that found the car ownership is consistently associated with the lower rates of active travel among children aged below 18 year old. Studies have suggested as income grows, demand for faster and more comfortable transport means will increase, which leads to an increase in motorized. The demographic dataset also shows that income and employment status determine people's decision to live in one particular residential areas such as in Bukit Jelutong.

This can be seen the comparison between households pattern in Bukit Jelutong and Seksyen 18 on income and employment status which Bukit Jelutong earners at RM 5,000 - RM 7,000 and the second highest earners are above RM 13,001. While most parents in 
Seksyen 18 earns at range RM 3,001 - RM5,000 (low to medium household income group). The findings suggest that the effect of household economic status on school choice of mode is indirect, through the employment composition of parents (either one) and parent's education background as it can be observed that employment and educational background among parents in Bukit Jelutong is far better compared to parents in Seksyen 18. This findings thus support the cited by Panter et al, (2010) that identified the high average income of household has fostered societal values and individual lifestyles that heavily depend on the vehicle over alternative modes of transport. They perceived driving could, therefore, be interpreted as a default option because walking was not perceived as possible.

Table 1: Descriptive statistics of participants in different neighbourhood by selected social characteristics

\begin{tabular}{|c|c|c|}
\hline Social characteristics & $\begin{array}{c}\text { SK Seksyen } 18 \\
n=162 \\
(\%)\end{array}$ & $\begin{array}{c}\text { SK Bukit Jelutong } \\
n=135 \\
(\%)\end{array}$ \\
\hline $\begin{array}{l}\text { Parents Education Background } \\
\text { Primary level } \\
\text { Secondary level } \\
\text { Certificate/Diploma/Bachelor Degree } \\
\text { Master degree/PhD } \\
\end{array}$ & $\begin{array}{c}3.3 \\
53.5 \\
35.2 \\
8.0 \\
\end{array}$ & $\begin{array}{l}3.0 \\
34.0 \\
51.1 \\
11.9 \\
\end{array}$ \\
\hline $\begin{array}{l}\text { Parents Occupation } \\
\text { Employed } \\
\text { Unemployed } \\
\text { Self-employed } \\
\text { Student } \\
\text { Housewife } \\
\text { Retired } \\
\end{array}$ & $\begin{array}{c}70.2 \\
0.2 \\
7.5 \\
0.0 \\
20.2 \\
1.9\end{array}$ & $\begin{array}{c}77.8 \\
0.7 \\
8.2 \\
1.5 \\
11.1 \\
0.7\end{array}$ \\
\hline $\begin{array}{l}\text { No. of car ownership } \\
1 \\
2-3 \\
\text { More than } 3\end{array}$ & $\begin{array}{l}52 \\
33 \\
15\end{array}$ & $\begin{array}{l}36 \\
49 \\
15\end{array}$ \\
\hline $\begin{array}{l}\text { Household Income } \\
\text { RM } 1,001 \text { to RM } 3,000 \\
\text { RM } 3,001 \text { to RM } 5,000 \\
\text { RM } 5,001 \text { to RM } 7,000 \\
\text { RM } 7,001 \text { to RM } 9,000 \\
\text { RM } 9,001 \text { to RM } 11,000 \\
\text { RM } 11,001 \text { to RM } 13,000 \\
\text { Above RM } 13,001\end{array}$ & $\begin{array}{l}24.5 \\
36.2 \\
27.0 \\
6.4 \\
3.4 \\
1.0 \\
1.5\end{array}$ & $\begin{array}{c}11.6 \\
10.0 \\
26.5 \\
9.6 \\
16.0 \\
6.0 \\
20.3\end{array}$ \\
\hline $\begin{array}{l}\text { Number of children in primary school } \\
1 \\
2 \\
3 \\
4 \\
5\end{array}$ & $\begin{array}{c}16.3 \\
37.1 \\
39.0 \\
3.5 \\
4.1 \\
\end{array}$ & $\begin{array}{l}43.7 \\
31.1 \\
13.3 \\
3.0 \\
6.7 \\
\end{array}$ \\
\hline $\begin{array}{l}\text { Children Gender } \\
\text { Boy } \\
\text { Girl }\end{array}$ & $\begin{array}{l}68.4 \\
31.6\end{array}$ & $\begin{array}{l}61.5 \\
38.5\end{array}$ \\
\hline
\end{tabular}

Essentially, it seems that children in both Seksyen 18 and Bukit Jelutong use a wider range of transport modes. Few $(0.5 \%)$ used public transport in both neighbourhoods, although there is a bus stop in front of the SK Bukit Jelutong (see Table 2). To understand the situation well, parents perceived the children are still young to walk without adult supervision. Associated with perceptions of age and neighbourhood environment is the notion of trust. Parents perceive an unacceptable level of confidence in their child's capabilities to negotiate road safety and respond to protect their children from any risks. Among those who use motorized transport to school, only $35 \%$ of those residing within a short walking distance (less than $400 \mathrm{~m}$ ) were driven. However, some researchers found that children from less deprived areas were more likely to walk or cycle to school than children from more deprived areas. This finding contradicts whereas children in Seksyen 18 more reasonable and have the freedom to active travel to school because of households' travel resources and budgets households Seksyen 18 only owned 1 car. Parents in Bukit Jelutong with the highest income (stable household financial) are more concerned about their children's safety for traffic, stranger danger, and crime.

Table 2: Associations between household income and choice of mode of transport to school for two different neighbourhood

\begin{tabular}{|c|c|c|c|c|c|c|c|c|c|c|c|c|c|c|}
\hline \multicolumn{15}{|c|}{ Mode of transport to school (\%) } \\
\hline \multirow{2}{*}{ Income } & \multicolumn{2}{|c|}{ Walking } & \multicolumn{2}{|c|}{ Cycling } & \multicolumn{2}{|c|}{ Van/school bus } & \multicolumn{2}{|c|}{ Car pooling } & \multicolumn{2}{|c|}{ Motorcycle } & \multicolumn{2}{|c|}{ Private vehicle } & \multicolumn{2}{|c|}{$\begin{array}{c}\text { Public } \\
\text { transportation }\end{array}$} \\
\hline & 1 & 2 & 1 & 2 & 1 & 2 & 1 & 2 & 1 & 2 & 1 & 2 & 1 & 2 \\
\hline RM1,001-RM3,000 & $\begin{array}{c}4 \\
2.4 \\
\end{array}$ & - & $\begin{array}{c}6 \\
3.7 \\
\end{array}$ & - & $\begin{array}{c}5 \\
3.0 \\
\end{array}$ & $\begin{array}{c}5 \\
3.7 \\
\end{array}$ & $\begin{array}{c}4 \\
2.4 \\
\end{array}$ & $\begin{array}{c}6 \\
4.4 \\
\end{array}$ & $\begin{array}{r}10 \\
6.1 \\
\end{array}$ & $\begin{array}{c}1 \\
0.7 \\
\end{array}$ & $\begin{array}{l}16 \\
9.8 \\
\end{array}$ & $\begin{array}{c}9 \\
6.7 \\
\end{array}$ & $\begin{array}{c}1 \\
0.6 \\
\end{array}$ & \\
\hline RM3,001-RM5,000 & $\begin{array}{c}7 \\
4.3\end{array}$ & - & $\begin{array}{c}4 \\
2.5\end{array}$ & - & $\begin{array}{c}6 \\
3.7\end{array}$ & $\begin{array}{c}7 \\
5.1\end{array}$ & $\begin{array}{c}3 \\
1.8\end{array}$ & $\begin{array}{c}2 \\
1.4\end{array}$ & $\begin{array}{l}13 \\
8.0\end{array}$ & $\begin{array}{c}1 \\
0.7\end{array}$ & $\begin{array}{c}18 \\
11.1\end{array}$ & $\begin{array}{c}5 \\
3.7\end{array}$ & - & - \\
\hline RM5,001-RM7,000 & $\begin{array}{c}2 \\
1.2 \\
\end{array}$ & $\begin{array}{c}2 \\
1.4 \\
\end{array}$ & $\begin{array}{c}2 \\
1.2 \\
\end{array}$ & - & $\begin{array}{c}6 \\
3.7 \\
\end{array}$ & $\begin{array}{c}17 \\
12.6 \\
\end{array}$ & - & $\begin{array}{c}5 \\
3.7 \\
\end{array}$ & $\begin{array}{c}2 \\
1.2 \\
\end{array}$ & $\begin{array}{c}1 \\
0.7 \\
\end{array}$ & $\begin{array}{l}11 \\
6.8 \\
\end{array}$ & $\begin{array}{c}10 \\
7.4 \\
\end{array}$ & - & - \\
\hline RM7,001-RM9,000 & 1 & - & 3 & - & 1 & 4 & - & 2 & 4 & - & 6 & 5 & - & 2 \\
\hline
\end{tabular}




\begin{tabular}{|c|c|c|c|c|c|c|c|c|c|c|c|c|c|c|}
\hline & 0.6 & & 1.8 & & 0.6 & 3.0 & & 1.4 & 2.4 & & 3.7 & 3.7 & & 1.4 \\
\hline RM9,001-RM11,000 & - & $\begin{array}{c}1 \\
0.7\end{array}$ & $\begin{array}{c}1 \\
0.6\end{array}$ & - & $\begin{array}{c}1 \\
0.6\end{array}$ & $\begin{array}{c}6 \\
4.4\end{array}$ & - & $\begin{array}{c}2 \\
1.4\end{array}$ & - & - & $\begin{array}{c}6 \\
3.7\end{array}$ & $\begin{array}{c}12 \\
8.8\end{array}$ & - & - \\
\hline RM11,001-RM13,000 & - & - & - & - & - & $\begin{array}{c}4 \\
3.0\end{array}$ & & - & - & - & $\begin{array}{c}3 \\
1.8 \\
\end{array}$ & $\begin{array}{c}3 \\
2.2\end{array}$ & - & $\begin{array}{c}1 \\
0.7\end{array}$ \\
\hline$>\mathrm{RM} 13,000$ & $\begin{array}{c}2 \\
1.2\end{array}$ & $\begin{array}{c}2 \\
1.2\end{array}$ & - & $\begin{array}{c}1 \\
0.7\end{array}$ & - & $\begin{array}{c}9 \\
6.7\end{array}$ & 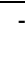 & $\begin{array}{c}2 \\
1.4\end{array}$ & $\begin{array}{c}1 \\
0.6\end{array}$ & & $\begin{array}{c}6 \\
3.7\end{array}$ & $\begin{array}{c}8 \\
6.0\end{array}$ & - & - \\
\hline
\end{tabular}

*1- Seksyen 18

*2 - Bukit Jelutong

\subsection{Children Mobility Pattern to and from School}

To understand the children mobility pattern and to what extent they have the freedom in choosing their mode of transportation to school, two important mobility pattern were analyzed; (i) active school travel, and (ii) independent mobility. Independent mobility among children can be defined as the geographical distance from home to places where they are allowed to wander when playing and socializing such as to school, shops or the playground. The active travel and independent mobility of 297 children were examined using data from the parental survey.

Focusing on the school travel from home, it is impossible that the impact of neighbourhood characteristics on children's active transport (e.g. walking and cycling) and socio-demographic background may vary according to the level of independent mobility. According to Table 3, the highest percentage of the mode of transport to school for Seksyen 18 is the private vehicle (41.4\%), which means their parents drive most school children, and the second-highest score is the motorcycle. While in Bukit Jelutong, the highest percentage of transportation mode to the school is also private vehicle and van/school bus both are scored $38.5 \%$. Some parents found that taking children to school by car or the children take a van/school bus is more convenient, safe, and time-saving. Increased use of the car as the most natural travel mode for children results in less independence. These reasons associate well with parents' sociodemographic background in Bukit Jelutong, whereas they have the affordability for budget and resources (e.g. financial, time and cars).

The result shows that $21.0 \%$ of children in Seksyen 18 have access to active school travel while fewer children in Bukit Jelutong $(4.4 \%)$ actively travel to school. As explained above, the parents prefer to drive their children or take a van/school bus for convenience and safety reasons. Ironically, the transport option in Bukit Jelutong has more frequent transport options compared to Seksyen 18. The finding reports that $2.2 \%$ of children take public transportation slightly highest compared to public transportation by children in Seksyen 18. The school's location is in the centre of the neighbourhood and quite far (approximately 800 meters) for children to walk to the main road to access public transportation. The highest score active school travel of Seksyen 18 was taken to indicate how far their parents were allowed their children to walk or cycle from home to school without adult supervision. This, to hypothesize, may increase their level of active transport, which demonstrated that children who encounter fewer mobility restrictions have high levels of active transportation.

Table 3: Active school travel to and from school

\begin{tabular}{|c|c|c|c|c|}
\hline \multirow{2}{*}{ Mode of transport } & \multirow{2}{*}{$\begin{array}{l}\text { Seksyen } 18 \\
n=162 /(\%)\end{array}$} & \multirow{2}{*}{$\begin{array}{c}\text { Bukit Jelutong } \\
n=135 /(\%)\end{array}$} & \multicolumn{2}{|c|}{ Active school travel (\%) } \\
\hline & & & Seksyen 18 & Bukit Jelutong \\
\hline Walking & $18(11.1)$ & $5(3.7)$ & \multirow{2}{*}{21.0} & \multirow{2}{*}{4.4} \\
\hline Cycling & $16(9.9)$ & $1(0.7)$ & & \\
\hline Van/school bus & $20(12.3)$ & $52(38.5)$ & & \\
\hline Car pooling & $7(4.3)$ & $19(14.1)$ & & \\
\hline Motorcycle & $33(20.4)$ & $3(2.2)$ & & \\
\hline Private vehicle & $67(41.4)$ & $52(38.5)$ & & \\
\hline Public transportation & $1(0.6)$ & $3(2.2)$ & & \\
\hline
\end{tabular}

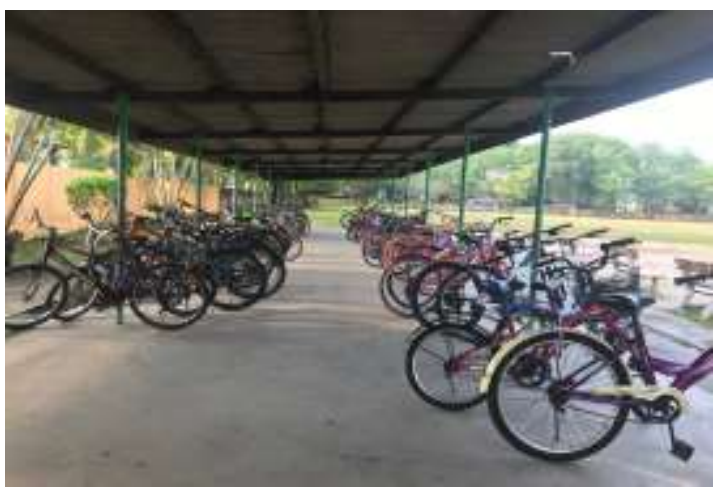

Fig. 3: The shaded and safe bike parking inside the school.

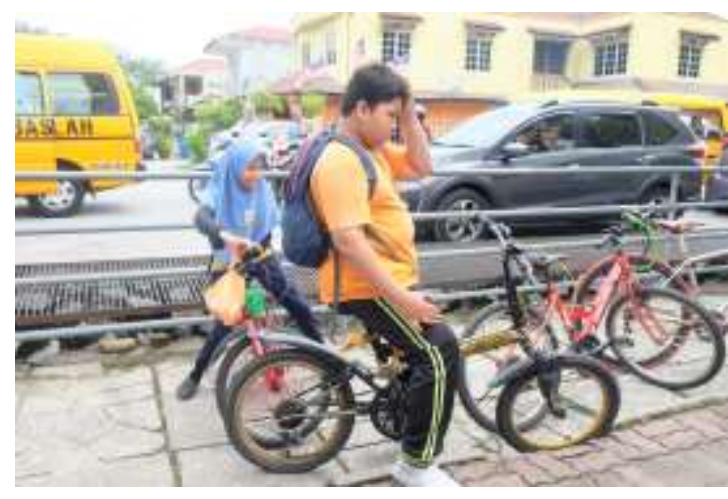

Fig. 4: Both boys and girls of school children in SK Seksyen 18 have equal access to bicycle.

The findings present that the number of children in both neighbourhoods had equal access to bicycle and walk (refer to Table 4). In Seksyen 18, the children slightly have more access to bicycle and equal for boys and girls (see Fig.4) since half of them who live within 800 meters actively travel to school by bike (20\%) and this support by the good bike infrastructures as the school provides the 
shaded and safe bike parking as shown in Fig. 3. School's initiative of providing the bicycle infrastructures became a motivation for the school children to cycle to school while enjoying cycling with their friends. According to the researcher observational notes, most parents (mostly are their father) have picked their children from school by motorcycle due to the short distance from home to school, quick and less space use for parking in front of the school. However, this finding is contrary to the observation, whereas most of the children's transportation mode in SK Bukit Jelutong is by private vehicle and van/school bus. When the parents were asked about the children access to bicycle and walk, the parents agreed. Still, they allow the children to walk or cycle as it convenience for recreational purpose only or to their friend's house in the same neighbourhood parcel.

Table 4: The distribution of children access to bicycle and walk

\begin{tabular}{|l|c|c|}
\hline Access to bicycle and walk & Seksyen 18 (\%) & Bukit Jelutong (\%) \\
\hline The child has access to bicycle & 55.2 & 50.6 \\
\hline The child has access to walk & 44.8 & 49.4 \\
\hline
\end{tabular}

From the findings of the choice of mode above, it can be said that the private car is a mode of transportation that is the most convenient transportation as our city is car culture oriented. The parents also prefer to ride the motorcycle as it is faster and practical (don't need parking space) as the distance of home is close to the school. This current lifestyle requires changing the behaviour of children driven to school but live close enough to walk. To better understand children's mobility pattern in school, this research also assessed the reasons for driving children to school and parents could choose more than one reason as presented in Table 5. The most reason given by the parents in Seksyen 18 for driving children to school is safety which includes road, neighbourhood and safety in front of the school. Other than concern on safety, convenience, and time-saving are among the frequent reasons cited by the parents when we're asked why they drove their child to school. The reason for time-saving is also highest among parents in Bukit Jelutong. Their responses for driving children to school emphasized the relative time advantage of driving over walking or cycling. For example, some parents mentioned "we save 5 to 10 minutes driving" and "parents running late" as they dropped off their children on their way to work. Besides, half of the parents who drove their children less than 800 meters to school did not allow their children to walk without adult supervision and refuse to take time to accompany their children to school. As discussed earlier, households' socio-demographic background in Bukit Jelutong demonstrates that they have a strong budget (e.g. time, money) for driving children to school. In this way, budget moderates with convenience, whereas the parents perceive that driving their children to school is the most convenient mode to school. Compared to Seksyen 18, most of Bukit Jelutong parents don't have any road safety issues, neighbourhood safety and safety around the school. They perceived that Bukit Jelutong is safer for their children to live, learn and play. Due to their concern about time and convenience, they prefer most to drive their children to and from school.

Table 5: Reasons parents choose for driving children to school less than 800 meters

\begin{tabular}{|l|c|c|}
\hline Parent Reasons' & Seksyen 18 (\%) & Bukit Jelutong (\%) \\
\hline Concern on road safety & 21.4 & 12.7 \\
\hline Convenience & 24.0 & 25.0 \\
\hline Neighbourhood safety & 30.2 & 13.6 \\
\hline Safety around school & 21.6 & 12.1 \\
\hline Time-savings & 27.5 & 33.3 \\
\hline Distance to school & 17.8 & 11.8 \\
\hline Budget (e.g. time, money) & 14.2 & 27.2 \\
\hline Household resources (e.g. cars) & 18.1 & 18.5 \\
\hline Trust in children/teach children to be independent & 16.7 & 14.3 \\
\hline Health issue & 3.3 & 6.7 \\
\hline Climatic & 5.9 & 5.2 \\
\hline
\end{tabular}

*the total does not sum to $100 \%$ because multiple responses were allowed

A child's independent mobility was measured using information from the parental survey. The parents were asked, "Do you allow your children to go out on their own or with friends without adult supervision? According to the results in Table 6, half of the parents in Bukit Jelutong and Seksyen 18 allow their children to wander around the neighbourhood without adult supervision within the distance of less than 800 meters. However, when the distance increase, the percentage of independent school travel getting decreased. We can conclude that the independent school travel is not dependent on how the walkable neighbourhood has been designed. The most important factor that influences parents' willingness to allow their children to be active independently is the distance that will be further discussed in the following topic - how distance can be associated with the choice of mode. The parents are paranoid about their children safety to allow them to active independent wander around in neighbourhood without adult supervision when the distance more than 1.6 $\mathrm{km}$. The parents found the distance that more than 800 meter is out of children's capability to walk or cycle alone or with their friends. Most of the parents did not allow the children to be independent because of their concern on road safety, neighbourhood safety and safety around the school. It should be noted that in Bukit Jelutong, the houses are strata landed scheme (gated and guarded). The parents may only allow the children to wander around within the neighbourhood parcel or the neighbourhood playground. Compared to Seksyen 18, the type of houses is a low-cost terrace with non-gated and guarded - children have more freedom to wander in their neighbourhood. The situation is the same as in Bukit Jelutong, which is the parents still worry about the children's safety and not trust their children's capabilities to walk or cycle without adult supervision. 
Table 6: Level of independent school travel to and from school

\begin{tabular}{|c|c|c|}
\hline Distance & Seksyen $18(\%)$ & Bukit Jelutong (\%) \\
\hline$<400$ meter & 28.7 & 29.8 \\
\hline $400-800$ meter & 25.4 & 23.4 \\
\hline $800 \mathrm{~m}-1.2 \mathrm{~km}$ & 14.3 & 18.6 \\
\hline $1.2 \mathrm{~km}-1.6 \mathrm{~km}$ & 17.8 & 13.8 \\
\hline $1.6 \mathrm{~km}-2.0 \mathrm{~km}$ & 5.7 & 10.9 \\
\hline $2.0 \mathrm{~km}$ & 8.1 & 3.5 \\
\hline
\end{tabular}

Table 7 shows that the more distance increased, the mode of choice for both schools are the same. This finding is not surprising given the body of previous reviews demonstrating this relationship. Other than driven their children to school, parents in Bukit Jelutong prefer their children taking a van/school bus for reasons of convenience such as to avoid walking or cycling in the rain although the distance to school would be acceptable for walking or cycling. However, the walkable neighbourhood in Bukit Jelutong does not guarantee that the children will walk or cycle to school. It can be seen that in every distance categories, less frequent children in Bukit Jelutong walk or cycle to school compared to children in Seksyen 18 although when the distance to school is more than $800 \mathrm{~m}, 20 \%$ of the children are walking and cycling. The results of choice of mode of transport in SK Bukit Jelutong representing a high level of car dependence as the distance less than $400 \mathrm{~m}$, the percentage of van/school bus, car-pooling, motorcycle and private vehicle gradually increase when the distance increased. This situation can be analysed their socio-demographic background and how far the parent trusts their children's capabilities to active independent travel to school with their own. As said, 16\% of parents in Seksyen 18 trust their children to be independent because they are having a constraint in the budget includes time and money.

Table 7: The relationship between distance from home to school and mode of transport to school

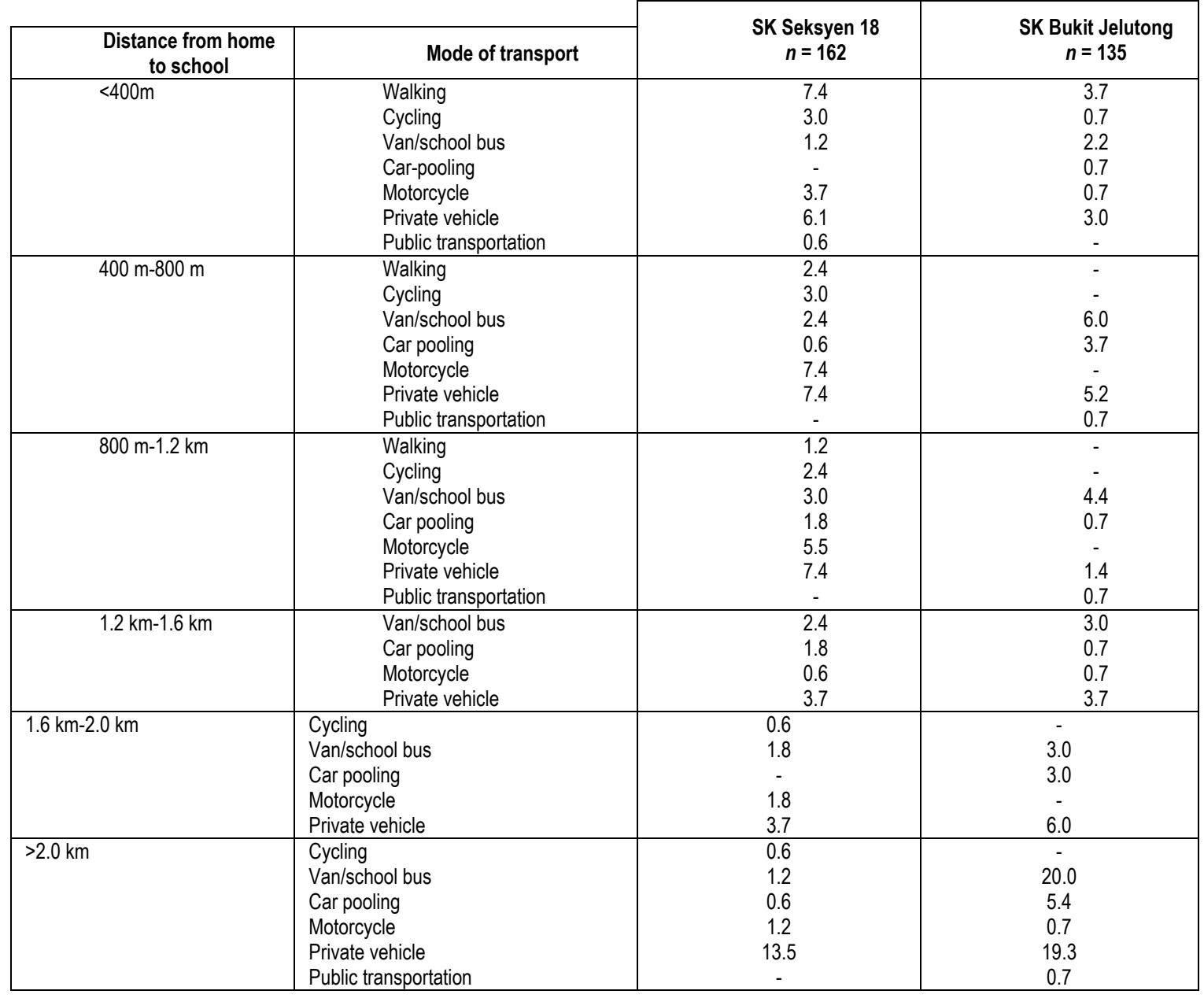

The research further discussed to examine to what extent school location may affect parents' choice of mode. Figure 3 and 4 above shows the distribution number of children attending school in every distance from home to school. It can be seen that the concentration pattern occurred in Seksyen 18 whereas the number of children moderates increase for a distance of more than 800 meter. The parents in Seksyen 18 are preferred to send their children to nearby school (neighbourhood school) - within their neighbourhood as it provided by the guidelines - one primary school for 10,000 population. While the distribution of the number of children in Bukit Jelutong shows a greater increase when the distance from home to school increase to $1.6 \mathrm{~km}$. This proves that $40 \%$ of the children are not residing in Bukit Jelutong. 


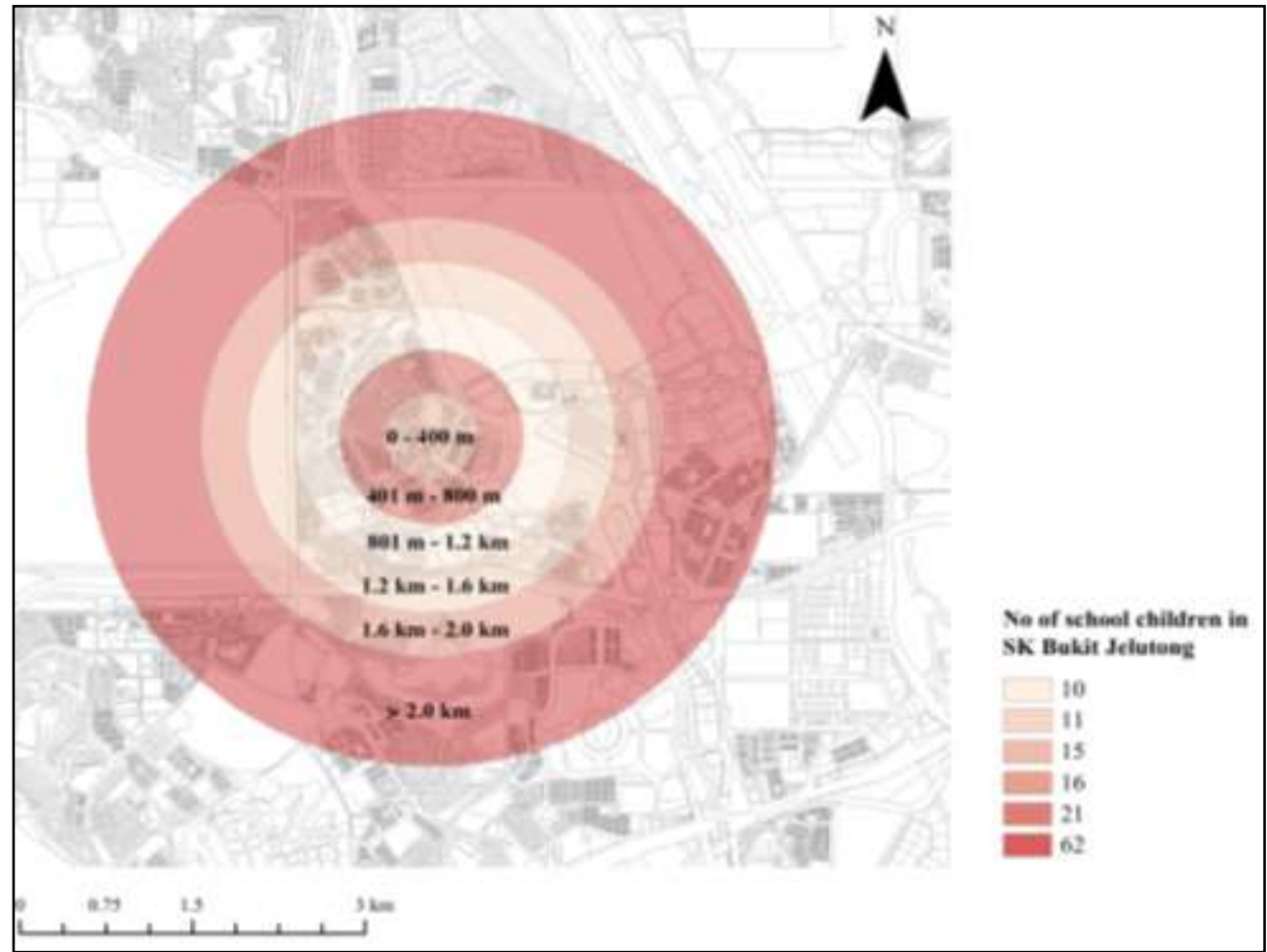

Fig. 4: SK Bukit Jelutong with well-known school profile reduces the importance of distance from home to school among the parents

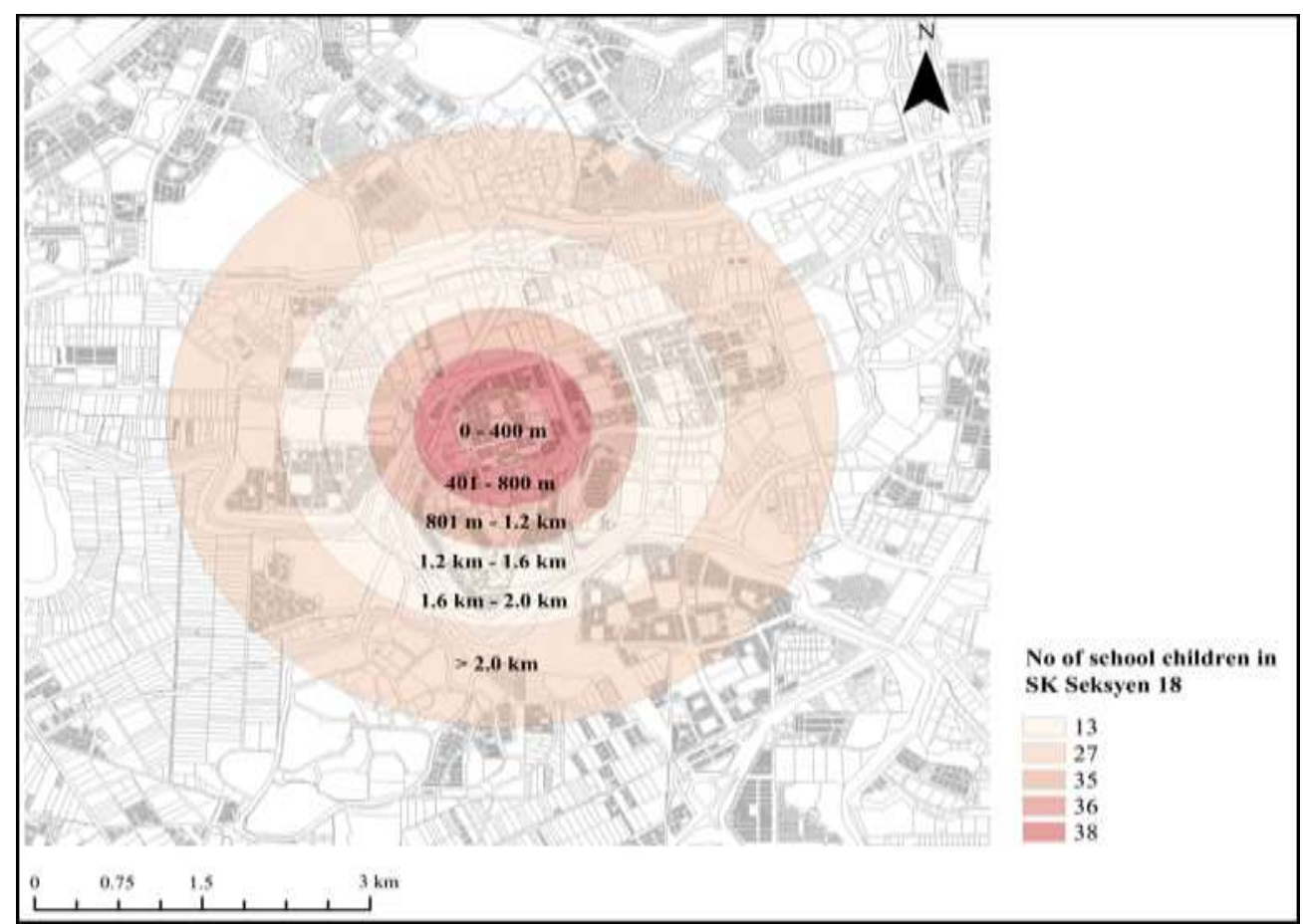

Fig. 5: Parent choose to send their children to a common profile of school like SK Seksyen 18 that are located in the catchment area as the distance is an important factor for school choice.

Some of them are living outside Bukit Jelutong such as Puncak Perdana, TTDI Jaya and Seksyen 13. The research suggests that the parents do not consider the distance from home to school, but more prefer the school reputation as SK Bukit Jelutong is a School of Excellence Cluster (Sekolah Kluster Kecemerlangan) with excellent achievement in a national examination such as UPSR. This is reasonable since there is a strong increase in the number of student's intake every year in this school. There is a possibility for most of 
the students who live outside Bukit Jelutong to travel to school by car. In this analysis, it shows that besides the strong factors such as distance and density, the school's profile is affecting the school choice as well.

In recent reviews, there was a strong correlation between socio-economic status and the growth of intelligence from infancy through adolescence because having the financial stability could ensure that the parents can afford to provide the best education facilities to their children (McDonald and Aalborg, 2009). This is a very interesting topic for future research on this changing trend of parent preferences and how neighbourhood physical interventions may lead to a sustainable mode share in car-oriented environments in Malaysia.

Given this emphasis on the situation, parents of SK Bukit Jelutong evaluate the reputations of the schools when deciding their desirability of being a "good parent" - overprotective and fear to accident or crime. They preferred the quality of schools and the social environment and concerning their child's education. It can be observed that school effectiveness or parents may rationally choose schools with school and student's performance, parent involvement in school and school facilities plays an important role in the decision of choice of mode to and from school.

\subsection{Parent Perceptions on Neighbourhood Characteristics}

The neighbourhood environment within a child lives is likely important in determining parent decision about school travel modes because a child and their parents come into daily contact with it. The descriptive statistics of the parental perceived neighbourhood built environmental characteristics are given in Table 8. In both cases, the results do not have many differences, although the neighbourhood concept and the residential density is different. More than half of the parents in Section 18 describe that they found the streets and intersections density is unsafe for their children to walk or cycle to school. A recurring observation was the number of cars on the street and the attitude of the drivers. Parents residing in Shah Alam were concerned more about the speed of traffic. However, the significant different perception between the two neighbourhoods is the traffic volume. 54.3\% of the parents in Seksyen 18 agreed that the traffic volume in their neighbourhood is heavy due to the mix of land uses around school compared to the traffic volume in the neighbourhood of Bukit Jelutong as Bukit Jelutong was designed as a walkable neighbourhood. However, from the observation, the traffic volume in Seksyen 18 is moderate, but the vehicle's speed is something that parent's concern about. It may be that increased residential densities are associated with increased levels of automobile traffic and crime, which increase danger and might be decreased walking and cycling among children particularly. The highest percentage of both cases' perceptions are worrying about danger, especially when the population is increased in the high-density area. Furthermore, this finding of the neighbourhood characterized by concern on the danger of traffic, speed of the vehicle, children safety - crime, and traffic facilities to assist active travel is positively associated with the level of independent mobility of school children.

Table 8: Parental perception on built environment in the neighbourhood

\begin{tabular}{|c|c|c|}
\hline Built environmental perceptions & $\begin{array}{c}\text { SK Seksyen } 18 \\
n=162 /(\%)\end{array}$ & $\begin{array}{c}\text { SK Bukit Jelutong } \\
n=135 /(\%)\end{array}$ \\
\hline Pedestrian walkway is narrow, uncovered and disconnected & 46.3 & 51.1 \\
\hline Traffic congestion in front of the school is because of the parent's vehicle & 86.4 & 80.0 \\
\hline Effective crosswalk and traffic lights help students to cross busy roads & 76.5 & 80.0 \\
\hline There are barrier to walking in my neighbourhood & 36.4 & 41.5 \\
\hline Traffic volume in my neighbourhood is heavy & 54.3 & 37.0 \\
\hline Most drivers go too fast while driving in my neighbourhood & 48.8 & 54.8 \\
\hline The distance between intersections in my neighbourhood is short & 59.9 & 50.4 \\
\hline There are shops and restaurants I can walk to in my neighbourhood & 65.4 & 57.8 \\
\hline The roads are unattractive enough for a child to walk/cycle & 59.9 & 47.4 \\
\hline I am worried about my child interacting with strangers & 87.7 & 87.4 \\
\hline People are out and about, talking and doing things with one another & 64.8 & 56.3 \\
\hline
\end{tabular}

*1- Seksyen 18

*2 - Bukit Jelutong

*the total does not sum to $100 \%$ because multiple responses were allowed

They were asked on how to improve the situation in the school area, most of them pointed towards traffic calming, segregated bike lane, and more safety. One of the parents mentioned make the school area car-free, make the bike lane and pedestrian pathway safer and connected, and provide less parking spaces outside school areas to avoid traffic congestions during the after school hour. Others stressed on creating better signage and traffic management. Though it was not only traffic-related reasons that contributed to lower perceived safety levels. Additionally, social and environmental factors were associated with a lower perceived school area safety. In line with the presence of stranger danger to be causes of parental paranoid concerning their children's safety in the neighborhood. A greater sense of community, so too, may relate to higher sociability and the attenuation of safety concerns.

Note, these findings have been quantified by pointing out that the association perceived between density and distance may represent significant causality. To explain these findings, the debate that in low density residential and destinations are related to each other which then limits the need to travel even in the shorter distance and makes independent mobility less attractive. This similar debates to higher density setting that travel demand results in road congestion and parking issues especially in front of schools that the neighbourhood design for car-centric. If attitudes towards built environment qualities are more important to determine the children travel behaviour, this has implications for policymaking and design phase. At the critical scenario, land uses (the practice if mixed land uses) condition and 
zoning favourable to car-oriented thus not be sufficient to support the child-friendly environment (to allow kids more independence at an earlier age), especially for school areas.

\subsection{Conclusion}

Strength of this research provides the large sample size and comparing between two different neighbourhoods that reveal whether children's or parents' concern differs across different residential; low (less deprived area) and medium density (deprived area). As stated above, these surveys are not directly comparable, as both the sample sizes are different. But, the results from two neighbourhoods at differences that probably can be associated with the distance as the most important factor for discrimination between modes of transport to school due to the school closure and socio-demographic consequences.

In summing up this research, the results showed that a child was more likely being driven by parents to school although the school location has been designed within walking distance. The mode of walking to and from schools found more common among children in low and middle-income neighbourhood (or deprived area) due to the socio-demographic factors and distance. However, we cannot neglect the parental fear of crime and road safety towards the neighbourhood environment when the distance increased especially in many criminal cases involving children happened in Malaysia recently. Neighbourhood density is positively associated with mode of choice, even after accounting for travel distance. The result shows the parents' decision-making process concerning school distance from home can be seen as comprising several important decision: the decision about the number of kilometres, school profile and fear of crime in neighbourhood environment and road safety.

The research concludes that among 10-12 year old children, the parental perceptions of neighbourhood environmental characteristics are most associated with distance and convenience aspect. This may be important for urban planners and policymakers to make a well-considered decision concerning built environmental redevelopments of existing neighbourhoods and planning for a new neighbourhood. Other than the issue of built environmental characteristics, when concerning road safety, this will deal with the relevant policymaking as these results may have vital implications for policies regarding walking practices among school children. We need to shift away from the car-culture or normalize car for the children in school zones. The school zones should be the safest places to walk or bike, not the opposite. Besides, walking and cycling, forms of active travel have the potential to contribute significantly towards physical activity among children and the environment has shown that environmental factors play a role in determining children travel behaviour. Significantly, the results indicate that the built environment at the school trips (home-to-from) has a stronger association with the choice of mode and influence parents decision-making and are essential to the development of effective planning interventions especially in cycling infrastructures around school. When kids can ride, everyone can ride. This has renewed interest in children's lives in cities within the field of social sciences, geography, planning and design. Themes such as the importance of outside play, sustainable mode share, urban health and safety, are pushing the role that planning can play in the creation of child-friendly cities. In doing so, future research will need to consider the residential and road design aspects, intensity and quality of the mix land uses, to provide a better conclusive explanation for the association between the current and committed land uses in the neighbourhood and choice of mode for school commuting that may ultimately together they make decisions regarding school transportation mode.

\section{Acknowledgements}

The author gratefully acknowledge the support of Universiti Teknologi MARA and Institute of Research Centre under the Lestari grant 600-IRMI 5/3/Lestari (039-2018).

\section{References}

Broberg, A., and Sarjala, S. (2015). School travel mode choice and the characteristics of the urban built environment: the case of Helsinki, Finland. Transport Policy, 37, $1-10$.

Curtis, C., Babb, C., and Olaru, D. (2015). Built environment and children's travel to school. Transport Policy, 42, 21-33.

De Meester, F., Van Dyck, D., De Bourdeaudhuij, I., and Cardon, G. (2014). Parental perceived neighborhood attributes: associations with active transport and physical activity among 10-12 year old children and the mediating role of independent mobility. BMC Public Health, 14(1), 631.

He, S. Y., and Giuliano, G. (2017). Factors affecting children's journeys to school: a joint escort-mode choice model. Transportation, 44(1), 199-224.

Ikeda, E., Stewart, T., Garrett, N., Egli, V., Mandic, S., Hosking, J., and Smith, M. (2018). Built environment associates of active school travel in New Zealand children and youth: a systematic meta-analysis using individual participant data. Journal of Transport and Health, 9, 117-131. 
Kyttä, M. (2004). The extent of children's independent mobility and the number of actualized affordances as criteria for child-friendly environments. Journal of Environmental Psychology, 24(2), 179-198.

Larsen, K., Buliung, R. N., and Faulkner, G. E. (2015). School travel route measurement and built environment effects in models of children's school travel behavior. Journal of Transport and Land Use, 9(2).

McDonald, N. C., and Aalborg, A. E. (2009). Why parents drive children to school: implications for safe routes to school programs. Journal of the American Planning Association, 75(3), 331-342.

Mitra, R., and Buliung, R. N. (2015). Exploring differences in school travel mode choice behaviour between children and youth. Transport Policy, 42, 4-11.

Rothman, L., Buliung, R., To, T., Macarthur, C., Macpherson, A., and Howard, A. (2015). Associations between parents' perception of traffic danger, the built environment and walking to school. Journal of Transport and Health, 2(3), 327-335.

Rojas Lopez, M. C., and Wong, Y. D. (2017). Children's active trips to school: a review and analysis. International Journal of Urban Sustainable Development, 9(1), 7995.

Sarmiento, O. L., Lemoine, P., Gonzalez, S. A., Broyles, S. T., Denstel, K. D., Larouche, R., and Hu, G. (2015). Relationships between active school transport and adiposity indicators in school-age children from low-, middle-and high-income countries. International Journal of Obesity Supplements, 5(S2), S107.

Schoeppe, S., Duncan, M. J., Badland, H. M., Alley, S., Williams, S., Rebar, A. L., and Vandelanotte, C. (2015). Socio-demographic factors and neighbourhood social cohesion influence adults' willingness to grant children greater independent mobility: A cross-sectional study. BMC public health, 15(1), 1-8.

Sharmin, S., and Kamruzzaman, M. (2017). Association between the built environment and children's independent mobility: A meta-analytic review. Journal of Transport Geography, 61, 104-117.

Stewart, O. (2011). Findings from research on active transportation to school and implications for safe routes to school programs. Journal of Planning Literature, 26(2), $127-150$

Urry, J. (2016). Mobilities: new perspectives on transport and society. Routledge.

Waygood, E. O. D., and Susilo, Y. O. (2015). Walking to school in Scotland: do perceptions of neighbourhood quality matter? IATSS Research, 38(2), 125-129. 